\title{
Dubbing Viewers in Cyberspaces: A Netnographic Investigation of the Attitudes of a Persian-language Online Community
}

KOME - An International Journal of Pure Communication Inquiry Volume 8 Issue 1, p. 23-43. (C) The Author(s) 2020

Reprints and Permission: kome@komejournal.com Published by the Hungarian Communication Studies Association DOI: $\underline{10.17646 / \text { KOME. } 75672.45}$

\section{Saeed Ameri and Masood Khoshsaligheh}

\section{Department of English, Ferdowsi University of Mashhad, IRAN}

\begin{abstract}
It appears that online communities have provided a free and user-friendly platform for users to do many real-time pieces of stuff from doing translations to discuss translations. The field of translation studies has begun to investigate these online virtual environments for varied perspectives. Nevertheless, the existing research has mainly addressed fansubbing communities. The present investigation, however, analyzed a Persian-language online community where its users exchanged comments and shared ideas regarding dubbing in Iran. For the purposes of this study, netnography, as a reliable research method within the marketing discipline and communication studies, was employed to study the community and its members. The collection and analysis of posts and comments from this online community yielded new insights into Persian dubbing and how Iranian dubbing audiences view Persian dubbing. On another level, the study provided evidence supporting the application of netnography as a methodological tool in investigating reception in audiovisual translation.
\end{abstract}

Keywords: Netnography; dubbing; reception; Iranian viewers; participant observation; online community

\section{Introduction}

Since the inception of translation studies (TS), varied and original investigative methods have been introduced into the discipline, including Internet-mediated, sociological and ethnographic approaches (Saldanha \& O'Brien, 2013). Notwithstanding the recognition of the validity and legitimacy of the new approaches in TS, research has barely benefited from the full potentials of other approaches, such as ethnography. Only a few projects in the TS literature, as Asare (2016) observes, are firmly grounded on ethnographic or participant observation approaches. The limited research, which has employed ethnography (e.g. Angelelli, 2004; Koskinen, 2008; Asare, 2011; Olohan \& Davitti, 2017) has, by and large, put under scrutiny the translators' role in organizations, their working process and the tools exploited in their workplace (Asare, 2016). With the rapid technological growth and the shift towards Internet-mediated interactions on social networking websites in the 2000s, traditional ethnographic methods were no longer able to enrich our understanding of such a social media life (Kozinets, 2015). Therefore, netnography or online ethnography as "a technique for the cultural analysis of social media and online community data" (Kozinets et al. 2014, p. 262) came into existence. Although the role 
of the Internet and the new technology has been well-recognized in TS (e.g. Chan, 2015), the application of netnography in the field has been limited. Dombek (2014) and Li (2015) are the only researchers who have applied the method for the exploration of online non-professional translation. This has also triggered the acknowledgement of netnography in seminal TS literature (e.g. Pérez-González, 2014; Jiménez-Crespo, 2017). The present changes in the audiovisual translation (AVT) landscape as well as users' new habits and tastes have foregrounded the importance of researching audience "in their real-life settings" to have "a better understanding of the role of AVT in their daily lives" (Li, 2019, p. 384).

A considerable body of dubbing reception research (e.g. de los Reyes Lozano, 2015; Perego et al. 2015; Ameri et al. 2018; Di Giovanni \& Romero Fresco, 2019; Mehdizadkhani \& Khoshsaligheh, forthcoming) has resorted to experimental designs or self-report data. However, netnography could offer fascinating insights into a given phenomenon as it occurs naturally (Kozinets, 2019) and natural data "are neither elicited by nor affected by the actions of social researchers" (Potter 2006, p. 191). The quantitative and experimental nature of previous studies on audience, according to $\mathrm{Li}$ (2019), is very restrictive and research should embrace new and novel methods, such as netnography.

Overall, using netnography as its method, this paper sets out to contribute to dubbing reception scholarship through analyzing an online Persian community where Iranian dubbing viewers voice their ideas and attitudes towards dubbing. To do so, viewers' comments and opinions, as online narratives, posted on the forum were studied. For a better appreciation of netnography, the next section sketches its main features and procedures. It then outlines the limited existing research in TS, which has used netnography.

\section{Netnography}

Netnography was originally introduced in the late 1990s by Robert V. Kozinets for exploring online content in marketing and consumer disciplines (Kozinets, 2019). Defined as "participant-observational research based in online fieldwork", netnography encompasses a textual analysis of people's views and perspectives made online on social network platforms (Kozinets, 2010, p. 60). Netnogrpahy is, therefore, "a pragmatic, how-to, workbench-level approach to studying social media using a cultural lens" (Kozinets, 2019, p. 19). This qualitative research method is brand new and has quickly gained ground across disciplines: tourism, sociology, leisure studies, and education, among others. Grounded on fieldwork, netnography presents a full account of online and Internet-based communities or culture (de Valck et al. 2009, p. 197). In other words, it allows investigators to gain the perspectives of online gatherings in which individuals "present themselves using digital rather than physical referents" (Schau \& Gilly, 2003, p. 385) and actively communicate and commune with each other like a socio-cultural group (Kozinets, 2010). In addition to being time-efficient and inexpensive, netnography incorporates a multitude of naturally occurring behaviors. It is also less obtrusive, and is conducted in less fabricated situations accounting for far-reaching, permanent access to the informants (Kozinets, 2015).

There exist some similarities and differences between netnography and traditional ethnography. The two practices aim to uncover "human experience and cultural understanding", "deep appreciations of the context of people's everyday life", and "social systems of shared meaning" (Kozinets, 2019, p. 15). Both are naturalistic and open-ended practices and are carried out in an authentic situation, but the former is faster, simpler, more time-efficient, and affordable. Ethnography demands the physical presence of the investigator; nonetheless, more demographic information as well as numerous non-verbal clues could be obtained (Kozinets, 2006a, 2010, 2019). To provide a systematic contextualization of data, the 
netnographer is supposed to have high interpretive skills. The researcher is also supplied with the ready-made transcription of the information, which is far easier in many ways for the analysis (Kozinets, 2006a, 2010). The significant quality standards of netnography, as mentioned by Kozinets (2006a, p. 286), include "immersive depth, prolonged engagement, researcher identification, and persistent conversations".

A netnographic study may benefit from three forms of data (Kozinets, 2006b, 2010):

- Field notes are obtained through the researcher's inscription and direct observation of the community and its members.

- Archival data are achieved from the textual analysis of pre-existing messages, posts, comments, pictures, etc. on the community.

- Elicited data are collected through interviewing or chatting with the members of the community.

To guarantee an in-depth netnographic investigation, as Kozinets (2006b, 2010) spells out, the netnographer has to follow a series of steps carefully:

The first step is planning and entrée. Finding appropriate online communities is the first step of the procedure to address research questions. Therefore, research goals and the targeted online forum should match. Once the community is identified, specific points are considered germane in the selection of the community for research: if it has relevant information and data for the purposes of the study, if a substantial amount of posts is available, if rich data can be accessed, and if a certain amount of interactions among the members could be found. In addition, before taking the next step, the researcher should spend some time exploring the online community to get oneself familiarized with it. The second step is the collection of the data in the form of field notes, archival or elicited data, as elaborated earlier. As there is a great volume of information on online forums, the netnographer should decide which data best fit the research goals. Data collection should continue as long as no new information is found and saturation is reached. The third step concerns data analysis; the netnographer may choose a specific qualitative data analytical technique, such as thematic analysis or grounded theory. Another stage involves the measures for trustworthy interpretation. To ensure that, the netnography should be carried out with long-term engagement, and the results should be equipped with feedback from the members. Generalizing the findings beyond the given group should be done with caution and supported with a triangulated design and long-term immersion in the community. More importantly, conclusions of a netnographic research should be made realistically in the light of the limitations of the project. Ethical procedures in netnography encompass (a) revealing the researcher's presence and goals in the community, (b) keeping the anonymity of members in the research, (c) requesting feedback from members on results, and (d) seeking members' permission for anything which may be directly quoted. Finally, the results are suggested to be sent to members, particularly those whose posts have been examined to lend more insights.

To the best of our knowledge, netnography has been employed only in two large-scale projects in TS which are summarized in Table 1. 
Table 1 - Summary of the netnographic research in TS

\begin{tabular}{|c|c|}
\hline \multicolumn{2}{|c|}{ Dombek’s (2014) netnographic study of Polish crowdsourcing } \\
\hline Goals & $\begin{array}{l}\text { The author aims to "understand the motivation underpinning } \\
\text { contributions that are typically without financial reward, especially } \\
\text { when the call for translation is made by a for-profit entity" (xvi). }\end{array}$ \\
\hline Methodology & Kozinets (2010) \\
\hline Instrumentation & $\begin{array}{l}\text { online questionnaires, observation, retrospective } \\
\text { think-aloud protocol }\end{array}$ \\
\hline Community or group & Polish Facebook user-translators \\
\hline Duration & 1 October 2011- 2 March 2013 \\
\hline Type of collected data & Elicited data, archival data, field notes \\
\hline Researcher's activity & Personal interactions with the members of the group \\
\hline
\end{tabular}

Li's (2015) netnographic study of Chinese fansubbing

Goals The author investigates "the dynamics of collective identity formation in The Last Fantasy (TLF) fansubbing group" and demonstrates "how TLF's fansubbers deploy digital technologies" for their works (8).

Methodology Kozinets (2010)

Instrumentation online questionnaires, observation

Community or group TLF fansubbing

Duration Not mentioned

Type of collected data Elicited data, archival data, field notes

Researcher's activity Active participation in group conversations as well as translating or proofreading subtitles for the group

As can be inferred from Table 1, the limited existing research, which has benefited from netnography, has been confined to the area of fansubbing and crowdsourcing with a strong emphasis on translators than audiences. Nevertheless, there is still much room for further applications of netnography in AVT, especially at present when online environments and social media are booming. This in turn has brought about new chances for audience of cinematic products to "voice their opinions in a way that had never previously been possible" (Chiaro, 2014 , p. 206). The application of netnography in translation, however, has not been straightforward. Li (2015), for instance, reports that the activities of the community under the investigation can go beyond its specific website and members may perform on multiple platforms. Additionally, Dombek (2014) adds that the data offered by a netnographic study sound compelling albeit insufficient, suggesting the incorporation of other relevant methods. She also argues that some users may not willing to share the messages, which they exchanged with other users, with the researcher even though they were assured of the confidentiality of the data. Overall, the potentials and capabilities of netnography in TS could be summarized as allowing researchers to study a phenomenon in its natural setting which could yield first-hand and fresh insights. In spite of this, the small body of netnographic literature has so far been limited to translation processes as well as social agents, especially translators. There is, however, ample room for using netnography in reception studies.

\section{Dubbing reception studies}

In consideration of the importance of audience, a rapidly growing amount of what can be called AVT reception studies has been published in the current decade (Di Giovanni \& Gambier, 
2018), with an emphasis on subtitling and media accessibility, and dubbing has received lesser attention (Chaume, 2013; Di Giovanni, 2018). The remarkable contributions into dubbing reception have so far focused on experiments and surveys with self-report data (e.g. Fuentes Luque, 2003; Chiaro, 2007; Antonini, 2008; de los Reyes Lozano, 2015, Perego et al., 2015; Ameri et al., 2018,; Ameri \& Khoshsaligheh, 2018; Khoshsaligheh et al., 2018; Di Giovanni and Romero Fresco, 2019). The importance of qualitative research on audience is that researchers could employ a wide array of tools, ranging from interviews to participating observation, and it guarantees the investigation of audience behaviors "in as natural a condition as possible" (Di Giovanni, 2018, p. 163).

We know from the literature that the reception of both dubbing and subtitling is comparable as far as audience understanding and cognitive efforts are concerned (Perego et al., 2015) but dubbing may offer a more relaxed and less cognitively demanding viewing experience on the part of audience in case the cinematic program is complex (Perego, Missier, \& Stragà, 2018). In his doctoral dissertation, de los Reyes Lozano (2015) found that children might not experience a great deal of difficulty in understanding cultural content, which is typically left untouched in dubbing. In a Polish context, Leszczyńska and Szarkowska (2018) came to this conclusion that Poles prefer domestication in dubbing cartoons, implying that the use of Polish elements in dubbed versions, which eradicated the trace of the original culture, is acceptable to them. Additionally, in Iran, audience pay much attention to such issues as synchronization, voice-quality and censorship, and translational issues do not seem to dominate the reception of dubbing (Ameri et al., 2018; Ameri \& Khoshsaligheh, 2018). They also prefer to watch the dubbed versions, which highlight the color and foreignness of the original. In an ongoing study by Ameri (forthcoming), it was revealed that the matter of foreignization and domestication highly depends on the program genre. For example, Iranians would rather watch animated films with dubbing because the translations are highly domesticated as elements from the Iranian culture are usually used which makes the program more enjoyable and funny. This is also the case for Koverienè and Satkauskaitè's (2018) reception studies into Lithuanian dubbing. The authors argue that Lithuanians preferred to watch animated films with dubbing rather than voice-over and subtitling because of "the illusion that a film [the dubbing] is a local product" (p. 82), and this is achieved through careful synchronization and voice-selection. Although survey studies claim that Iranian audience are critical of poor synchronization and incorrect voice-selection for performance, an eye-tracking research shows that Italian dubbing viewers look less at the characters' mouths and direct their attention towards eyes. This is perhaps because they know that synchronization is barley perfect and they still want to immerse in the program and enjoy the experience (Di Giovanni \& Romero Fresco, 2019). To wrap up this discussion, dubbing reception has stirred up much interest among researchers, leading to the publication of survey-based or experimental studies. Yet, within this framework, it would be difficult, if not impossible, to reach a critical understanding of dubbing audience in their natural setting where they feel free to share and voice their attitudes about merits and demerits of dubbing.

\section{Method}

This study attempts to analyze how Iranian audiences perceive Persian dubbing in an online community. To offer the analysis of dubbing reception from a fresh outlook, the present investigation draws on netnography. For this purpose, the steps of conducting netnography including planning and entrée, data collection and analysis, trustworthy interpretation, ethics and member checks (Kozinets, 2002, 2006b, 2010) were followed. A brief description of the stages is presented in the following. 


\section{Planning and entrée}

To explore the reception of Iranian dubbing viewers, a forum-based online community at http://cafeclassic5.ir/ (CCL) was investigated which hosts 7000 members. CCL requires registration, and select users with high ranks and credits are allowed to make new posts while ordinary members can only like and comment on the posts. CCL undertakes reasonably high traffic and hosts an increasingly huge amount of data. One section of CCL is also about dubbing and subtitling. Prior to data collection, the first researcher reviewed the terms and conditions of CCL to ensure the existing rules. CCL warns against the use of materials without proper citations (due reference to CCL). In addition to acknowledging CCL in every part of this paper, an initial request was also sent to the site managers in order to obtain their consent for using material for research purposes. The site managers approved the request and the registration on CCL was conducted on 26 March 2015. The first author of the paper spent several weeks to gain a comprehensive understanding of the regulations on CCL and to acquire a general overview of CCL. The members were Iranian, and the language of communication among the members was Persian, the official language in Iran.

\section{Data collection}

Attempts were made to gather all three forms of data. While collecting the archival data, the researcher also gathered field notes data by observing and participating in some discussions by liking and commenting. The researcher maintained an active role rather than a silent observer. In order to make a clear understanding of the vague posts and comments, the site members were contacted although in some cases the certain user who posted the comment was no longer active in the forum. After several weeks of probing the community to get a good understating of it, the process of data collection and analysis began and continued for twenty months, and the immersion in the forum ended in mid-November 2016. Some elicited data were also gathered through a questionnaire survey. The questionnaire included six open-ended questions and over 25 members of the website were asked to contribute; however, only 20 members at the end returned their responses. The questions were designed to gain more-in-depth insights into the picture already drawn through the field notes and the archival data.

\section{Data analysis}

The archival data were copied and downloaded from the website and saved on a hard disc. Employing 'thematic analysis', the data were coded and memoed manually. This qualitative data analysis technique allows for pinpointing and analyzing the shared themes within the data (Braun \& Clarke, 2006). These themes and codes were not established in advance but were developed as a result of continuously-examination of the existing data. The quotations used as evidence were translated into English and on occasions, some were shortened because of their length. The field notes data included several pages of written reports and snapshots of the website that the netnographer made. The process of data analysis started after collecting some data so that an initial picture of the topic could be drawn to get the ball rolling. The identified codes and patterns were updated whenever new data were added and analyzed. The data were textual materials and required no transcription. The elicited materials were also coded through 'thematic analysis'. 


\section{Ethical considerations and member checks}

As to the legal considerations governing research on human participants, prior to the research, permission and approval for conducting this research was obtained from our University's research ethics committee. Any research carried out within this institution should be conducted in accordance with the approved codes of ethics. For example, researchers are required to maintain the confidentiality of information gathered from human subjects. We attempted to maintain the highest standards of research ethics.

Concerning the ethical considerations governing netnography, the netnographer's presence, affiliations and intentions were publically stated on his account on CCL. The necessary permission for using CCL material for research was secured from the site managers. It should be noted that this is a public website and anybody on the Internet can access the posts. We aimed to seek consent from the members for quoting their narratives in the paper, but it was not possible since some members were no longer active. To solve this problem, we avoid using the alias or name of the producer of the narratives and only an English translation of the Persian narrative is reported. As to the elicited data, the respondents were informed of the research goals, and their anonymity was also ensured in the report. For getting feedback from the participants, member checking was employed. However, due to the busy schedule of users and their little interest in examining the findings, very few agreed and cooperated with the study.

\section{The findings}

Given the purpose of the study, the data from the field notes and especially archival data were mainly used for analysis and conclusions. The elicited data are also presented but due to the length of the paper, the details are not reported.

\section{Field notes results}

Field notes data include findings acquired through the netnographer's observation of the community and these can include subtexts, pretexts, environment and setting, and personal emotions aroused during the research (Kozinets, 2002, 2006b, 2010). CCL is mainly devoted to films, yet there are also some subsections on music and literature. As the focus of the current project was on dubbing, the participating author joined the Art of Dubbing and Subtitling section. CCL holds particular rules and regulations, and new members have to carefully follow them. The members are also required to have cinematic alias, selected based on the names of an actor, film director or scriptwriter. For instance, the participating author chose the name Viggo Mortensen. After registration is completed and the profile is up, the users should inform the managers of their registration on CCL and one forum is devoted to this matter where the users introduce themselves and provide some background information and discuss their aims. For the present study, the participating author introduced himself and fully elaborated on the aim of the investigation.

There is a perfectly close relationship among the members of the forum. There is a message box at the top of the CCL home page where the users greet and welcome each other or introduce the new topics they have posted. The messages in the box show that there is a reasonable degree of rapport and warm relationship among the members. The participating author who was observing CCL actively contributed to some discussions. He both posted comments and commented on other posts. Since he has studied translation, his posts mainly revolved around film translation. To give an example, he posted a topic on translation of taboo expressions in 
the Persian dubbed version of the film Pulp Fiction (1994) and received ten scores for his activities. The users did appreciate his activities on translation-related topics.

\section{Archival data results}

Archival data include the posts and comments of the users in the community. Kozinets (2006b, 2010) challenges a simple downloading and collection of data which is a form of invisible participation and is more like 'lurking'; instead, he advocates constructive engagement and involvement in the community, including a regular reading of posts, rating, thanking, and commenting. For him, a simple downloading of the posts or messages without any social contacts might yield narrow and superficial findings. As discussed previously, the participating author tried to have an active role in the community and posted serval posts and comments. However, they were not included in the data analysis, and the necessary data were gathered through elicited approaches. He also tried to avoid challenging the ongoing discussions so as not to affect the natural process of discussing issues on the forum.

The forum specifically analyzed for this netnographic project was the Art of Dubbing and Subtitling in which 33 topics were addressed by the users; an overall of 4400 responses or comments were made and exchanged. This is to note that not all comments were used in the present study since some data were irrelevant and did not serve the purpose of the research. Off-topic comments and posts were therefore discarded. A careful analysis of all relevant topics, posts, and comments through coding and categorizing led to the emergence of three main themes and several basic codes (Table 2).

Table 2: An overview of the emerged themes

$\begin{array}{ll}\text { Themes } & \begin{array}{l}\text { codes } \\ \text { dubbing actors, dubbing directors, dubbing companies, } \\ \text { Voice-acting }\end{array} \\ & \begin{array}{l}\text { redubbing, dubbing in satellite channels } \\ \text { Translation for dubbing }\end{array} \\ \text { Subtitling } & \text { subtitling disadvantages, translation mistakes }\end{array}$

Voice-acting

Voice-acting, "the performance and dramatization of the dialogues" by dubbing actors (Chaume, 2012, p. 19), dubbing directors and actors received much attention in the forum which fueled much debate among the members. The members were keen on commenting on the performance of dubbing actors and they talked about specific topics, such as to what extent a given dubbing cast chosen by a certain dubbing director was appropriate. This is partly because, for the viewers, "actors and their bodies are central to performance" (Bosseaux, 2015, p. 213). Additionally, Bosseaux (2015) has empirically shown that the (bad and wrong) selection of dubbing actors for performance can greatly affect the way characterization is achieved in dubbing. Overacting and underacting are generally discouraged in the dubbing industry (Chaume, 2007b) yet overacting has been a recommended option for Persian dubbing, most notably cartoons. The Iranian dubbing director and actor Alireza Bashkandi, however, points out that in his dubbing for the Korean TV series Jumong (2006-2007), he discouraged his dubbing cast from exaggerating in their performance (Vaeziepour, 2009). 'Para-verbal means' of acting including voice quality, speed, and intonation, among other means (PérezGonzález, 2014, p. 199) might be highlighted by the viewers as they affect their reception and enjoyment of the program. 
The users of CCL were also very concerned with character synchrony-the agreement between the original actor and dubbing actor in terms of their age, gender and voice qualities (Fodor 1976) - which has also been emphasized in dubbing by Tahami (2011) and Bosseaux (2015). A user, for example, comments:

The voice of Jalilvand no longer matches the role and physique of Robert De Niro in this film [Killing Season 2013]. Esmaili and Bahram Zand should have been chosen for acting.

Or a combination of positive and negative views in this comment:

I watched the second part of this film series [The Hobbit: The Desolation of Smaug 2013]. The dubbing team was not my cup of tea. Choosing the voice of Shervin Ghatei for Bilbo Baggins's role was not good at all. Mr. Samsami should have employed a more fresh voice like Kasra Kiani for this role. [...] Concerning the voice of Gollum, Amir Mohammad Samsami beautifully imitated the voice and performance of the late Amir Hooshang Ghatei [who dubbed Gollum in The Lord of the Rings 2001-2003] so that the viewer cannot spot the change of the dubbing actor.

What could be inferred from other comments is that users were more fascinated by the skilled and experienced dubbing actors exclusively those who had been in the industry for quite a while, and they did not favor newcomers to the industry. For instance, a member wrote:

These days whenever we see such amateur voices, we more prize the value of the old dubbing actors. It seems that fast foods and easy, electronic life have affected people's voices. Why don't we have all those rough, husky voices, stentorian voices, [and] heavenly voices among all the new voices anymore?

This is also evident in another user's remarks:

I've mentioned many times that the golden era of Persian dubbing has ended. Those intelligent, gifted and dedicated dubbing actors are no longer available; where are people like Ali Kasmai, Houshang Latifpour, Iraj Doustar? Houshang Latifpour and Fahimeh Rastegar and Bijan Mofid were famous in the dubbing industry, but how about now?

What is inferred from such remarks is that dubbing viewers are not very satisfied with the current output of dubbing in Iran partly because of the dearth of established talents and partly because the young dubbing talents have not yet reached a reasonable level of competency. Alireza Bashkandi is of the same mind on this issue and believes that a large number of young inexperienced dubbing actors have found a chance to enter this industry just because of wrong policies (Jafar Pourkami, 2012).

Although it was pointed out that the new generation of dubbing actors do not have a way with acting, some other members held a differing view. For the latter group, the young dubbing actors should be given opportunities to join the dubbing industry because the established dubbing actors will not always be available, and a young generation should be trained to pass the torch. In supporting this view, a member says:

All I said was that we should acknowledge that the great practitioners of dubbing would not be with us forever. So we need new talented voices from the younger generation. We 
should encourage those who can continue this art. This new generation, that some looked down on, should and will continue this endeavor. The future generations will admire this group as we admired the past generation.

Such views are also mirrored in Keikavoos Yakideh's opinions-who is an Iranian seasoned dubbing actor. He supports the idea of hiring new voices, albeit he thinks that they should be well-trained and develop adequate competences during their internship (Yakideh 2008). He also rejects the overuse of well-known voices for dubbing - resulting from not hiring new talents - as this may lead to the "so-called radio-play effect", a situation when a dubbing actor dubs many voices (Zabalbeascoa et al 2001, p. 107).

Moreover, this was pointed out that in a TV series like Prison Break (2005-2017) in which 250 characters played major and minor roles, it does not sound reasonable to have the series dubbed by a small dubbing cast. This is perhaps due to the cost of dubbing as Whitman-Linsen (1992, 13 cited in Chaume 2012, p. 20) remarks: "The dubbing industry is notorious for kowtowing to economic expediencies, a wont painfully apparent in the often mediocre results of their work".

Another discussion on voice-acting was related to the replacement of a dubbing cast with another between dubbings in the case of movies which are screened in several installments like Harry Potter (2001-2011). The users complained that each part was dubbed wih a different dubbing cast even though the protagonists were the same. The excerpt below reflects this view:

Since the dubbing cast varies in Harry Potter film series, the movies should be dubbed again and the same dubbing actors should be employed.

The dubbing companies may not live up to such an expectation as some dubbing actors might decide to terminate their contract with the company for reasons best known to themselves. The economic consequences of limiting a dubbing talent to a given actor, however, should not be overlooked as Bosseaux (2019, p. 231) questions whether dubbing actors could earn a living with this condition.

Additionally, members associated the low level of quality in current Persian dubbing with personal issues among agents, such as the low income or lack of respect for them. In the following excerpt a user elaborates more:

Low payment, insecurity of voice-acting occupations, favoritism, jealousy, pride, less motivation among the newly-employed dubbing actors are among the reasons that have led to the low quality of dubbing in recent years.

Likewise, dubbing companies and their managers were the subject of discussions. They commented that in dubbing companies, the programs for dubbing are (self-) censored to a great extent that often a large portion of the plot is missed or altered. Dubbing directors, dubbing actors and translators are expected to be chosen according to their work quality and skill levels, yet connections and nepotism, as stated by the members, constitute the core of criteria in Iran. There were dozens of complaints that blockbusters are not dubbed or they are dubbed with some sort of delay. Similarly, a member briefly comments that:

[...] Shervin Ghatei is not suitable for this profession. His performance is really awful. Some guys believe that one should work a lot in this profession, but I don't agree because if the person who has no talent why should he/she remain in this profession as a dubbing actor? It's clear that he's been employed in this profession through nepotism and he only seeks fame. 
Moreover, the users noted that some dubbing directors are ill-suited for this job. They are not competent in fashioning the translation draft into a well-synchronized version, while synchronization is considered crucial in delivering a quality dubbing (Chaume, 2007b, 2012; Tahami, 2010). Carelessly-synchronized translations force the dubbing actor to read too fast or too slowly to fit the translation in the available time slot. A user expresses his/her opinions on the issue:

I think, dubbing a movie should be like an engineering work in that the formulas are devised based on past experiences and knowledge; otherwise it wouldn't work or would fail. A dubbing director shouldn't be only a dubbing actor, he must have a good command of cinema, synchronization techniques, language and culture of the country from which the original movie was originated.

This view is quite in line with those of the professionals and scholars who recommend that the dubbing director should have a good knowledge of cinema and its techniques, of story-telling and dialogue writing, among other necessities (Tahami 2010; Chaume 2012). More importantly, the dubbing director "is responsible for prompting, stimulating and instructing the actors to put on their best performances" (Whitman-Linsen, 1992, p. 82 cited in Chaume, 2012, p. 36)

As to dubbings on Persian-language satellite TV channels, it seems these dubbings less excite and interest users. Although satellite channels run on substantial budgets for their dubbed products, the poor quality of their dubbings, resulting from unavailability of professional dubbing talents for the channels, appears to be a serious deficiency. A critical user reflects on these issues:

When this [satellite] channel started its activity, I wanted to write a post about satellite channels in general, but I thought I should wait since they had recently started out and would gradually improve the quality of their dubbings. Although months have been passed since their initial work, their dubbing quality has not been developed but has been weakened. All the dubbing actors sound like amateur first-timers with no skills in the profession.

Dubbing on Persian-language satellite TV channels is an issue that Changiz Jalilvand, a dubbing director of great renown, also notes. For him, this is a real problem affecting the general dubbing industry in Iran (Naiemi, 2015). In addition, according to Ashkan Sadeghi, the poor quality of voice acting in such satellite channels is indicative of an incorrect assumption that voice acting is an easy job, thus, an option to anybody to begin as a career (Poursabagh, 2014).

Another criticism of dubbing was redubbing, that is, "the existence of a second, or subsequent, dubbed version of the same audiovisual text in the same target language" (Zanotti, 2015, p. 111, see also Chaume 2007a). The reasons for redubbing a program in Iran are usually associated with technical problems or ideological issues. For example, the animation Robin Hood (1973) has been dubbed multiple times in Iran; once due to ideological reasons involving the censorship of scenes that were not appropriate. Another time the redubbing was to improve the voice-acting and sound quality. Some members believed that it was necessary to dub some films again to improve the voice acting, sound quality and naturalness of the translated language. A user emphasizes:

As some talked about the redubbing of masterpieces like The Godfather (1972), I should stress that even these excellent dubbings could be redubbed to achieve better quality. It's 
good to do it when the best dubbing actors are still alive, so let such movies be dubbed again. It's not needed to translate all the dialogues again, they can work on the weakness of the previously dubbed dialogues to enhance the naturalness of the language.

However, there was some disagreement over the redubbing topic. For some, redubbing classics is not necessary or even a good idea as they had already been dubbed. Those users were not optimistic about the success of a new dubbing cast and that the new dubbed version might be subject to further censorship. Some also pointed out that some companies which redubbed some films overlooked an already existing high-quality dubbed version. In the same vein, a member mentions:

After some years, this film was redubbed under the supervision of Naser Tahmasb as the dubbing director. But I couldn't appreciate the new dubbing. The first dubbing had such a quality that words cannot express. The only merit of the second dubbing was dubbing the parts censored in the first version.

Overall, it stands out that the members are mesmerized by the quality of voice acting and almost exclusively attend to the choice of dubbing cast.

\section{Translation for Dubbing}

Translation-related subjects include censorship, mistranslation, and the low professional competence of translators, among others. To begin with, the users were of the view that the new translators are not familiar with the art and history of cinema nor those of dubbing. They do not have the required command of the Persian language and culture and are not proficient enough to render idiomatic and colloquial expressions:

I think you would also agree that nobody like Amir Zand (at least in recent years) has been capable of translating films with such challenging idioms! (Pulp Fiction 1994 is a good example). Amir Zand lived in England and the US, and studied cinema academically. Last night, I was watching the dubbed version of Good Will Hunting (1997). The idioms that Matt Damon and his friends used were translated very awfully or were replaced with inappropriate equivalents. As you said the colloquial expressions could only be understood and translated by a person very familiar with the original culture.

Censorship, due to the current policies in Iran, is inevitable in dubbed programs (Khoshsaligheh \& Ameri, 2016). Censoring translation, according to users, is the saddest reality in the Iranian dubbing. They indicated that translation played a pivotal role in understanding films, and omitting and altering the dialogues would effectively reduce the overall quality. Further analysis shows that for the members, translation should be exciting and attractive. For instance, they emphasized the necessity of translating songs, and stressed the appropriate choice of Persian words. These issues are reflected in the comments of two users:

I think the film [Gandhi, 1982] was dubbed entirely. Yet, the scenes associated with the conflict between the Muslim and Hindu have been removed in the dubbed version. This is a documentary-based drama and censorship severely suppresses the truth about the historical events.

The conclusion is that putting several dubbing actors together does not mean that dubbing is good; the translation is more important. 
Issues pertaining to translation mistakes were not sufficiently mentioned since it required the users' familiarity with the original language. However, some users were very conscious in this regard and brought to the fore mistakes which appeared in the official dubbings. To give an example, two users indicate:

A film that greatly suffers from inadequate translation is the lovely film Jack the Giant Killer (1962). The second dubbing of this film which was executed after the Islamic Revolution has numerous problems not only in terms of the narrative but also the characters' names which were directly translated into Persian. For example, the name Pendragon was translated as "the pen of dragon". The translator surprisingly didn't know that the names are not translated for their meaning.

One of the pitfalls of a poor translation is the translator who does not look up the words when necessary. The translator of the movie Sleeper (1973) by Woody Allen did not pay careful attention to the movie title. The word sleeper had several meanings and one meaning is "a person who sleeps". But the other meaning is "a spy or saboteur" [...] which seemed to be more appropriate for the movie. Therefore, a better translation equivalent for the title can be "Spy" or "Saboteur".

As mentioned previously, the interaction between the users is considerable and they tend to comment on each other's posts. For example, a user who did not accept the idea of mistranslation of the title of Sleeper (1973) points out that there is no right or wrong translation for titles because many dubbing companies may opt for a more literal translation for commercial purposes. In his/her words:

You disregarded the commercial screening of the film for the cinema or any other media. What could be said about Sleeper (1973) or any other film is that the film supplier or dubbing companies chose a literal translation for the title just for the sake of advertising so a mistranslation may be deliberately favored.

In summary, the "thresholds of acceptability" (Chaume, 2012, pp. 17-18) that the users appear not to tolerate are censorship and poor translation. More importantly, several dubbing directors have also complained about the low quality of the translations for dubbing in their interviews (for example see Moazan, 2015). An obvious reason is that AVT training is barely offered in Iranian translation programs, and research reveals that the way the only two-credit course on AVT is taught is far from satisfactory (Khoshsaligheh \& Ameri, 2017).

\section{Subtitling}

As for subtitling, the members noted that subtitles distract their attention, and they cannot focus on the visual, and dubbing can provide more media accessibility for more people. This is highlighted in a comment:

The movie has Persian subtitling but you would lose the visual information and it [subtitles] distracts your attention as you are busy reading the subtitles.

When it comes to non-professional subtitling, more negative remarks were raised even though some were really grateful to fansubbers for providing free translations for the latest films or TV series which are not usually dubbed in Iran or at least not any time soon after the original release. They were very concerned with literal translations, mistranslations, and the addition of 
unnecessary notes and commentaries in the translations by fansubbers. Two users have voiced their opinions in this way:

Today, every English language student with the help of a computer generates poor translation of the movie dialogues. We see subtitles which abound with word-for-word translation of idioms and proverbs, and typos, structural and grammatical mistakes are common.

That some people subtitle a film at no cost is not a bad idea but this is not acceptable to see poor translations that are damaging the Persian language. Subtitling a film at no charge does not mean that the subtitlers' works cannot be criticized.

Overall, it seems that some members are frequently distracted by subtitles and this in turn hinders their immersion and flow in the program. This finding is not supported by experimental evidence offered by the recent research that explains (non-) professional subtitling is not cognitively taxing and is well-received by the audience (Perego et al. 2015, Orrego-Carmona 2016). However, these conflicting findings can be justified by the fact that Iran is not a subtitling country and official subtitling for fiction content is almost non-existent, and aside from the exposure of the younger generation to subtitling, the Iranian audiences are not typically accustomed to reading subtitles and may prefer the convenience of listening to dubbed versions. Also, what is watched by the Iranians is the product of amateur subtitlers who are not obliged to comply with the subtitling standards (Ameri \& Khoshsaligheh, 2019). Yet, this should be stressed that the members of this community appeared not to be lay viewers as they do not simply watch the programs for the sake of sheer passing of time but they usually critically consider the program from varied perspectives. In addition to this, they are dubbing enthusiasts and do not tend to welcome subtitling unbiasedly. Further investigations are therefore recommended for examining these arguments through an experimental design.

\section{The elicited data findings}

To further examine Persian dubbing reception, an online Persian questionnaire was employed. The questionnaire contained six open-ended questions about the purpose of creating the present forum, the main focus on voice acting, the current quality of Persian dubbing, the current quality of Persian dubbing in comparison with other countries, the differences between dubbing by state-run studios, privately-run companies and satellite TV channels, as well as the reasons for choosing dubbing rather than subtitling. Due to space limitation, only three relevant questions are discussed here: the main focus on voice acting, the current quality of Persian dubbing and the reasons for choosing dubbing.

As for the initial issue, the users argued that the stars of the original programs are the actors not the directors or scriptwriters or other agents. People have the tendency to notice and admire what they 'see' and 'hear' only-if good to their perception-; therefore, after they hear the voice of the (dubbing) actors, they fail to realize and appreciate the work of other agents like the (dubbing) director. Several users believed that translation is a very specialized task, and they cannot comment on it because of limited command of the source language and unfamiliarity with translational issues to spot possible weaknesses or appreciate strengths. From this analysis, it appears that priority is accorded to dubbing talents in assuring the dubbing quality.

With regard to the second issue, which undoubtedly deserves more attention in future studies, they were asked to evaluate the current Persian dubbing and justify their opinion. Sadly enough, except for one user, all respondents made references to the poor quality. The exceptional respondent replied: “I don't watch many dubbings presently, but those I watch are 
not so bad, but the voices are not exceptionally memorable". As evident in Table 3 , the analysis of the participants' responses, concerning Persian dubbing quality, highlighted a range of defects which could be grouped under four broad headings: translation (mentioned by 4 members out of 20), voice-acting (by 12 members), dubbing directing (by 7 members) and policy (by 19 members).

Table 3: An overview of the emerged themes

\begin{tabular}{|c|c|c|}
\hline Themes & Codes & Translated extracts from the data \\
\hline Translation & Poor translations & $\begin{array}{l}{[\ldots] \text { inaccurate and erroneous translations }} \\
\text { and at times unrelated to images. }\end{array}$ \\
\hline \multirow[b]{4}{*}{ Voice-acting } & $\begin{array}{l}\text { Unskilled young dubbing } \\
\text { actors }\end{array}$ & \multirow{4}{*}{$\begin{array}{l}\text { In the past, the circle of dubbing actors was } \\
\text { too tight and few could enter this well-praised } \\
\text { industry. Now the circle has been widened } \\
\text { and many unskilled actors were hired. } \\
\text { I'm not into contemporary dubbings, I think } \\
\text { the voices are boring and not satisfying like } \\
\text { the past. } \\
{[\ldots] \text { the poor quality of the present dubbing }} \\
\text { can be attributed to several factors including } \\
\text { the lack of a variety of voices, frantic rush in } \\
\text { dubbing films, the unmotivated dubbing } \\
\text { actors because of the economic problems, } \\
\text { among other things and so on. }\end{array}$} \\
\hline & $\begin{array}{l}\text { A paucity of skillful } \\
\text { dubbing talents }\end{array}$ & \\
\hline & Boring voices & \\
\hline & $\begin{array}{l}\text { Unmotivated dubbing } \\
\text { actors }\end{array}$ & \\
\hline \multirow{7}{*}{$\begin{array}{l}\text { Dubbing } \\
\text { directing }\end{array}$} & Bad voice cast selection & \multirow{5}{*}{$\begin{array}{l}\text { This is a mark of disrespect to the viewers to } \\
\text { change a dubbing actor chosen for a character } \\
\text { after some episodes. This is precisely the case } \\
\text { with the dubbing cast of Don Chuck } \\
\text { Monogatari (1975-1975). }\end{array}$} \\
\hline & $\begin{array}{l}\text { Inconsistency in dubbing } \\
\text { cast for TV series }\end{array}$ & \\
\hline & $\begin{array}{l}\text { Working with a special } \\
\text { group of dubbing actors }\end{array}$ & \\
\hline & Poor synchronization & \\
\hline & $\begin{array}{l}\text { Unfamiliarity of dubbing } \\
\text { directors with English }\end{array}$ & \\
\hline & $\begin{array}{l}\text { Not keeping the same } \\
\text { dubbing actor for a well- } \\
\text { known actor across } \\
\text { different programs }\end{array}$ & \multirow{2}{*}{$\begin{array}{l}\text { When I hear the dubbed voice of a given } \\
\text { actor, I accept it. Yet, it is too difficult to } \\
\text { accept another voice for that character like } \\
\text { Saeed Mozaffari who is the dubbing actor of } \\
\text { Brad Pitt. }\end{array}$} \\
\hline & $\begin{array}{l}\text { Nepotism in choosing the } \\
\text { cast }\end{array}$ & \\
\hline & $\begin{array}{l}\text { Unfair competition among } \\
\text { dubbing companies }\end{array}$ & \\
\hline
\end{tabular}




\begin{tabular}{|c|c|c|}
\hline \multirow{8}{*}{ Policy } & Censorship & \multirow{8}{*}{$\begin{array}{l}\text { What is shown on TV is not really dubbing! } \\
\text { It is a poor product with the abundance of } \\
\text { scene censorship, not to mention the dirty and } \\
\text { distorted translations. Among the dubbing } \\
\text { companies of the private sector, Century } 21 \\
\text { Visual Media Company was always } \\
\text { committed to doing quality dubbings but this } \\
\text { has ceased in the past years. }\end{array}$} \\
\hline & Dubbing few blockbusters & \\
\hline & $\begin{array}{l}\text { The low income of the } \\
\text { dubbing agents }\end{array}$ & \\
\hline & $\begin{array}{l}\text { Migration and death of } \\
\text { celebrated voice talents }\end{array}$ & \\
\hline & $\begin{array}{l}\text { Inadequate training for } \\
\text { new dubbing talents }\end{array}$ & \\
\hline & $\begin{array}{l}\text { Frantic rush for dubbing } \\
\text { programs }\end{array}$ & \\
\hline & $\begin{array}{l}\text { Poor sound mixing } \\
\text { because of the lack of } \\
\text { state-of-the-art equipment }\end{array}$ & \\
\hline & $\begin{array}{l}\text { No control over the quality } \\
\text { of dubbings }\end{array}$ & \\
\hline
\end{tabular}

As the themes suggest, Persian dubbing is suffering from a range of problems, and some quality standards such as accurate translation, synchronization, acting, and sound mixing, among others, (see Chaume, 2007b) have not been maintained in Persian dubbings. Many of these defects could be prevented if each year the products of dubbing companies are sent for assessment so that the companies could be informed of the shortcomings to remedy in the years to come like what is customary in Spain (see Zabalbeascoa et al, 2001, p. 106).

As to subtitling, the archival data seemed to point out that subtitling is not probably favored by the users. An opinion in this regard from the elicited data supports this view:

Reading subtitles deprive the viewers of the pleasure of watching the film and may result in losing some scenes. The subtitles are not standard and abound with many mistakes distorting the viewer's comprehension of the film. The translations made for the dubbing hold a higher quality [...].

Other elicited data, however, reveal that several respondents opted for watching a subtitled version unlike what was initially assumed:

I prefer hearing the original voice of the characters because watching a film with original voices can better transfer the feeling of authenticity. Yet, if there is a very unique and beautiful dubbing such as Gone with the Wind (1939), A Streetcar Named Desire (1951) or Who's Afraid of Virginia Woolf? (1966), I would go with dubbing.

Although dubbing has gained more currency, it seems that the pitfalls of the Persian dubbing in terms of quality persuade viewers to resort to subtitling. Additionally, some respondents were partial to the dubbed classics because they were dubbed when the Persian dubbing industry was at its peak. A respondent maintains: 
If it is a classic film, its dubbing must be watched. This makes you feel nostalgic for old times.

Interestingly, a viewer completely disapproves of dubbing even the classics:

If you compare dubbings with the originals, you can quickly notice the insignificant changes made even in those well-praised dubbings. Thus, you will find the originals more suitable.

$\mathrm{He} /$ she also comments on subtitling:

Generally, I accept Dr. Kavousi's views that watching the original films is much better. These avid viewers of dubbing were all born in the 1970s and 1980s and were grown up with high-quality dubbings. In the past when Google Translate didn't exist, good subtitles were available. At the moment, I don't appreciate the work of subtitlers excepting those of four subtitlers (Amir Tahmasbi and Hossein Gharibi).

Although we were not able to obtain the demographic information of the informants, the impression during the fieldwork and the personal contacts we had with some members support the view that the users of this form were mainly in their 30s or 40s. Consequently, there might be a correlation between the age of the users and their AVT preferences. Empirical research, however, is needed to confirm this view.

It is notable that there was one case expressing that he/she would rather watch the programs only in their original language without Persian dubbing or subtitling:

Generally, I would like to watch the films and cartoons in their original versions. But it doesn't mean I don't have any respect for dubbing, on the contrary, I found dubbing more interesting than the original for some films.

This is acknowledged that the study focused on a specific group of dubbing viewers; therefore, the results are unlikely to be representative of the whole dubbing audience in Iran.

\section{Conclusion}

Building on netnography, attempts were made to describe and understand how Iranian viewers of dubbing appreciate and perceive Persian dubbing. The obtained data tend to support the functionality of netnography as an appropriate method to study what people do, say, etc. online. Previous research on dubbing, be it experimental or survey-based, did not provide any account of dubbing quality from audience perspectives. This study in turn showed that Persian dubbing is suffering from a range of shortcomings and defects, which may have resulted in the reduction of the number of people who may enjoy watching dubbing or even consider it as an alternative modality. It also revealed insights concerning such issues as voice selection, redubbing, and dubbing agents' competences, among others, which have been barely examined in AVT from a qualitative perspective. These findings support some tacit assumptions that Persian dubbing has lost its exceptional quality over time. Notwithstanding this, the results, although with some caution, can inform the industry to more critically reflect on the present dubbed programs, perhaps by implementing new policies and introducing modifications to meet the audience demands. The pedagogical implications of this article could not be overlooked. The results of the translational issues benefit translation trainers in their designing of the course content for 
AVT classes. Translation trainees' awareness and competences should be heightened to offer viewer-centered translations to cater for viewers with special demands.

Of particular significance is flagging the shortcomings of Persian dubbing, which can best serve as descriptive hypotheses to be corroborated by future large-scale surveys. Also due to the small size of the sample used in this inquiry, more in-depth qualitative research-especially conducted through semi-structured in-person interviews - can help yield more insights into Persian dubbing quality. In prospective studies, demographic information should be collected to better feed the interpretation of the results. Studies with experimental designs are highly recommended to gain greater insights into when viewers tend to reject or stand the "thresholds of acceptability" in terms of dubbing quality standards (Chaume, 2012). Given that the data were obtained from a purposefully-targeted community, the research does not assume generalizability of the findings into other settings, and further research is of necessity.

\section{References}

Ameri, S., \& Khoshsaligheh, M. (2018). Exploring the Attitudes and Expectations of Iranian Audiences in Terms of Professional Dubbing into Persian. Hermes, 57, 175-193.

Ameri, S., \& Khoshsaligheh, M. (2019). Iranian amateur subtitling apparatus: A qualitative investigation. Mutatis Mutandis, 12(2), 431-451. CrossRef

Ameri, S., Khoshsaligheh, M., \& Khazaee Farid, A. (2018). The reception of Persian dubbing: A Survey on preferences and perception of quality standards in Iran. Perspectives: Studies in Translation Theory and Practice, 26(3), 435-451. CrossRef

Angelelli, C. (2004). Medical interpreting and cross-cultural communication. Cambridge: Cambridge University Press.

Antonini, R. (2008). The perception of dubbese: An Italian study. In D. Chiaro, C. Heiss, \& C. Bucaria (Eds.), Between text and image: Updating research in screen translation (pp. 135-147). Amsterdam: The Netherlands: John Benjamins.

Asare, E. (2011). An Ethnographic Study of the Use of Translation Tools in a Translation Agency: Implications for Translation Tool Design. (Unpublished doctoral dissertation), Kent State University,

Asare, E. (2016). Ethnography of communication. In C. V. Angelelli \& B. J. Baer (Eds.), Researching Translation and Interpreting (pp. 212-219). Abingdon, England: Routledge.

Bosseaux, C. (2015). Dubbing, Film and Performance: Uncanny Encounters. Bern, Switzerland: Peter Lang.

Bosseaux, C. (2019). Voice in French dubbing: the case of Julianne Moore. Perspectives, 27(2), 218-234. CrossRef

Braun, V., \& Clarke, V. (2006). Using thematic analysis in psychology. Qualitative Research in Psychology, 3(2), 77-101. CrossRef

Chan, S.-W. (Ed.) (2015). Routledge rncyclopedia of translation technology. Abingdon, England: Routledge.

Chaume, F. (2007a). Quality standards in dubbing: A proposal. TRADTERM, 13, 71-89. .

Chaume, F. (2007b). La retraducción de textos audiovisuales. Razones y repercusiones traductológicas. In J. J. Z. Vera \& F. R. Noguera (Eds.), Retraducir: una nueva mirada. La retraducción de textos literarios y audiovisuales (pp. 49-63). Málaga: Miguel Gómez Ediciones.

Chaume, F. (2012). Audiovisual Translation: Dubbing. Manchester, England: St. Jerome. 
Chaume, F. (2013). Research path in audiovisual translation: The case of dubbing. In C. Millán \& F. Bartrina (Eds.), The Routledge handbook of translation studies (pp. 288-302). Abingdon, England: Routledge.

Chiaro, D. (2007). The effect of translation on humour response: The case of dubbed comedy in Italy. In Y. Gambier, M. Shlesinger, \& R. Stolze (Eds.), Doubts and directions in translation studies: Selected contributions from the EST congress, Lisbon 2004 (pp. 137-152). Amsterdam: The Netherlands: John Benjamins.

Chiaro, D. (2014). The eyes and ears of the beholder? translation, humor, and perception. In D. Abend-David (Ed.), Media and translation: An interdisciplinary approach (pp. 197219). Fakenham, England: Bloomsbury.

de Valck, K., van Bruggen, G. H., \& Wierenga, B. (2009). Virtual communities: A marketing perspective. Decision Support Systems, 47(3), 185-203. CrossRef

Di Giovanni, E. (2018). Dubbing, perception and reception. In E. Di Giovanni \& Y. Gambier (Eds.), Reception studies and audiovisual translation (pp. 159-177). Amsterdam, Netherlands: John Benjamins

Di Giovanni, E., \& Gambier, Y. (Eds.). (2018). Reception Studies and Audiovisual Translation. Amsterdam, Netherlands: John Benjamins.

Di Giovanni, E., \& Romero Fresco, P. (2019). Are we all together across cultures? An eye tracking study of original and dubbed films. In I. Ranzato \& S. Zanotti (Eds.), Reassessing dubbing: Historical approaches and current trends. (pp. 126-144). Amsterdam: John Benjamins.

Dombek, M. (2014). A study into the motivations of internet users contributing to translation crowdsourcing: the case of polish Facebook user-translators. (Unpublished doctoral dissertation), Dublin City University, Dublin, Ireland.

Fodor, I. (1976). Film dubbing: Phonetic, semiotic, esthetic and psychological aspects. Hamburg: Germany: Helmut Buske.

Fuentes Luque, A. (2003). An empirical approach to the reception of AV translated humour: A case study of the Marx Brothers' 'Duck Soup'. The Translator, 9(2), 293-306. CrossRef

Jafar Pourkami, N. (2012). In conversation with the dubbing actor of Jumong and Bruce Lee. Resalat. Retrieved from http://yon.ir/eCloQ

Jiménez-Crespo, M. A. (2017). Crowdsourcing and online collaborative translations: expanding the limits of translation studies. Amsterdam, Netherlands: John Benjamins.

Khoshsaligheh, M., \& Ameri, S. (2016). Ideological considerations and practice in official dubbing in Iran. Altre Modernità, 15(Special Issue), 232-250. CrossRef

Khoshsaligheh, M., \& Ameri, S. (2017). Didactics of audiovisual translation in Iran so far: Prospects and solutions. Paper presented at the National Conference on Interdisciplinary Approaches to Translation Education, Tehran, Iran.

Khoshsaligheh, M., Pishghadam, R., Rahmani, S., \& Ameri, S. (2018). Relevance of Emotioncy in dubbing preference: A quantitative inquiry. Translation and Interpreting, 10(1), 75-91. CrossRef

Koskinen, K. (2008). Translating institutions: An ethnographic study of EU translation. Manchester: St Jerome.

Koverienè, I., \& Satkauskaitè, D. (2018). Lithuanian viewers' attitude towards dubbed animated films. In O. Andreica \& A. Olteanu (Eds.), Readings in Numanities (pp. 6784). Cham, Switzerland: Springer.

Kozinets, R. V. (2006a). Click to connect: Netnography and tribal advertising. Journal of Advertising Research, 46(3), 279-288. CrossRef

Kozinets, R. V. (2006b). Netnography. In V. Jupp (Ed.), The Sage dictionary of social research methods (pp. 193-195). London, England: Sage. 
Kozinets, R. V. (2010). Netnography: Doing ethnographic research online. London, England: SAGE.

Kozinets, R. V. (2015). Netnography. In R. Mansell \& P. H. Ang (Eds.), The international encyclopedia of digital communication and society (pp. 1-8). New Jersey, NJ: John Wiley \& Sons.

Kozinets, R. V. (2019). Netnography: The essential guide to qualitative social media research (3rd ed.). Thousand Oaks, CA: Sage.

Leszczyńska, U., \& Szarkowska, A. (2018). "I don't understand, but it makes me laugh." Domestication in contemporary Polish dubbing. JoSTrans, 30, 203-231.

Li, D. (2015). Amateur translation and the development of a participatory culture in china -a netnographic study of the last fantasy fansubbing group. (Unpublished doctoral dissertation), The University of Manchester, Manchester, England.

Li, D. (2019). Ethnographic research in audiovisual translation. In L. Pérez-González (Ed.), The Routledge handbook of audiovisual translation (pp. 383-393). London, England: Routledge.

Mehdizadkhani, M., \& Khoshsaligheh, M. (forthcomming). Insertion or voice-off in rendition of graphic codes: An experiment in persian dubbing. Visual Communication.

Moazen, A. (2016, March). In conversation with Khosro Khosroshahi. Mehrnews. Retrieved from http://yon.ir/ekjid

Naiemi, A. (2015). A probe into the dubbing industry: A status quo. Retrieved from http://yon.ir/9Hf4t

Orrego-Carmona, D. (2016). A reception study on non-professional subtitling: Do audiences notice any difference? Across Languages and Cultures, 17(2), 163-181. CrossRef

Perego, E., Missier, F. D., \& Bottiroli, S. (2015). Dubbing versus subtitling in young and older adults: Cognitive and evaluative aspects. Perspectives: Studies in Translatology, 23(1), 1-21. CrossRef

Perego, E., Missier, F. D., \& Stragà, M. (2018). Dubbing vs. subtitling: Complexity matters. Target, 30(1), 137-157. CrossRef

Pérez-González, L. (2014). Audiovisual translation: Theories, methods and issues. London, England: Routledge.

Potter, J. (2006). Naturalistic Data. In V. Jupp (Ed.), The Sage dictionary of social research methods (pp. 191-193). London, England: SAGE.

Poursabagh, A. (2014). Dubbing on satellite channels. Vatanemrooz. Retrieved from http://yon.ir/qxaao

Reyes Lozano, J. d. 1. (2015). La traduction du cinéma pour les enfants : une étude sur la réception [The translation of cinema for children: A reception-oriented study]. (Unpublished doctoral dissertation), Jaume I University, Spain.

Saldanha, G., \& O’Brien, S. (2013). Research methodologies in translation studies. Manchester, England: St. Jerome.

Schau, H. J., \& Gilly, M. C. (2003). We are what we post? Self-presentation in personal web space. Journal of Consumer Research, 30(3), 385-404.

Tahami, A. (2010). جكونه فيلم دوبله كنيج? [How to dub a film?]. Tehran, Iran: Negah.

Vaeziepour, M. (2009). Bashkandi in conversation with Mehr. Mehrnews. Retrieved from http://yon.ir/2ki8n

Whitman-Linsen, C. (1992). Through the dubbing glass: The synchronization of American motion pictures Into German, French, and Spanish. Frankfurt, Germany: Peter Lang International Academic Publishers.

Yakideh, K. (2008). The necessity of hiring outstanding voices. Etemad. Retrieved from http://yon.ir/dMFaC 
Zabalbeascoa, P., Izard, N., \& Santamaria, L. (2001). Disentangling audiovisual translation into Catalan from the Spanish Media Mesh. In Y. Gambier \& H. Gottlieb (Eds.), (Multi) Media translation: Concepts, practices, and research (pp. 101-112). Amsterdam: John Benjamins.

Zanotti, S. (2015). Analysing redubs: Motives, agents and audience response. In R. B. Piñero \& J. Diaz Cintas (Eds.), Audiovisual translation in a global context (pp. 110-139). Chennai, India: Palgrave Macmillan. 